\title{
Insight into the maintenance of odontogenic potential in mouse dental mesenchymal cells based on transcriptomic analysis
}

Yunfei Zheng, Lingfei Jia, Pengfei Liu, Dandan Yang, Waner Hu, Shubin Chen, Yuming Zhao, Jinglei Cai, Duanqing Pei, Lihong Ge, Shicheng Wei

Background. Mouse dental mesenchymal cells (mDMCs) from tooth germs of cap or later stages are frequently used in the context of developmental biology or whole-tooth regeneration due to their odontogenic potential. In vitro-expanded mDMCs serve as an alternative cell source considering the difficulty in obtaining primary $\mathrm{mDMCs}$, however, cultured mDMCs fail to support tooth development as a result of functional failures of specific genes or pathways. The goal of this study was to identify the genes that maintain the odontogenic potential of mDMCs in culture. Methods. We examined the odontogenic potential of freshly isolated versus cultured mDMCs from the lower first molars of embryonic day 14.5 mice. The transcriptome of mDMCs was detected using RNA sequencing and the data were validated by qRT-PCR. Differential expression analysis and pathway analysis were conducted to identify the genes that contribute to the loss of odontogenic potential. Results. Cultured mDMCs failed to develop into well-structured tooth when they were recombined with dental epithelium. Compared with freshly isolated mDMCs, we found that 1004 genes were upregulated and 948 were downregulated in cultured mDMCs. The differentially expressed genes were clustered in the biological processes and signaling pathways associated with tooth development. Following in vitro culture, genes encoding a wide array of components of MAPK, TGF- $\beta / B M P$, and Wnt pathways were significantly downregulated. Moreover, the activities of $B d n f$, Vegfa, Bmp2, and $B m p 7$ were significantly inhibited in cultured mDMCs. Supplementation of VEGF $\alpha$, BMP2, and BMP7 restored the expression of a subset of downregulated genes and induced mDMCs to form dentin-like structures in vivo. Conclusions. Vegfa, Bmp2, and Bmp7 play a role in the maintenance of odontogenic potential in mDMCs. 
1 Insight into the maintenance of odontogenic potential in mouse dental mesenchymal cells based on transcriptomic analysis

4 Yunfei Zheng ${ }^{1,2 \#}$, Lingfei Jia ${ }^{1,2,3 \#}$, Pengfei Liu ${ }^{4}$, Dandan Yang ${ }^{4,5}$, Waner $\mathrm{Hu}^{1}$, Shubin $\mathrm{Chen}^{4}$,

5 Yuming Zhao ${ }^{6}$, Jinglei $\mathrm{Cai}^{4}$, Duanqing $\mathrm{Pei}^{4}$, Lihong $\mathrm{Ge}^{6^{*}}$, Shicheng Wei ${ }^{13^{*}}$

$7 \quad{ }^{1}$ Department of Oral and Maxillofacial Surgery, Laboratory of Interdisciplinary Studies, Peking

8 University School and Hospital of Stomatology, Beijing 100081, P.R. China

92 Department of Orthodontics, Peking University School and Hospital of Stomatology, Beijing 10 100081, P.R. China

$11{ }^{3}$ Central Laboratory, Peking University School and Hospital of Stomatology, Beijing 100081, 12 P.R. China

134 Institute for Stem Cell Biology and Regenerative Medicine, Guangzhou Institute of 14 Biomedicine and Health, Chinese Academy of Sciences, Guangzhou 510530, P.R. China

$15{ }^{5}$ Experimental Center of Pathogenobiology Immunology, Cytobiology and Genetic, College of 16 Basic Medical Sciences of Jilin University, Jilin, P.R. China

$17{ }^{6}$ Department of Pediatric Dentistry, Peking University School and Hospital of Stomatology, 18 Beijing 100081, P.R. China

\#These authors contributed equally to this work.

*To whom correspondence should be addressed:

Prof. Shicheng Wei 
24 Central Laboratory, Peking University School and Hospital of Stomatology, 22 Zhongguancun 25 Avenue South, Haidian District, Beijing 100081, P.R. China

26 Tel: +86-10-82195780

27 Fax: +86-10-82195780

28 E-mail: sc-wei@pku.edu.cn

29

30 Prof. Lihong Ge

31 Department of Pediatric Dentistry, Peking University School and Hospital of Stomatology, 32 Zhongguancun South Avenue 22, Haidian District, Beijing 100081, P.R. China

33 Tel: +86-10-82195780

34 Fax: +86-10-82195780

35 E-mail: gelh0919@126.com 


\section{ABSTRACT}

Background. Mouse dental mesenchymal cells (mDMCs) from tooth germs of cap or later stages are frequently used in the context of developmental biology or whole-tooth regeneration due to their odontogenic potential. In vitro-expanded mDMCs serve as an alternative cell source considering the difficulty in obtaining primary $\mathrm{mDMCs}$, however, cultured $\mathrm{mDMCs}$ fail to support tooth development as a result of functional failures of specific genes or pathways. The goal of this study was to identify the genes that maintain the odontogenic potential of mDMCs in culture.

Methods. We examined the odontogenic potential of freshly isolated versus cultured mDMCs from the lower first molars of embryonic day 14.5 mice. The transcriptome of mDMCs was detected using RNA sequencing and the data were validated by qRT-PCR. Differential expression analysis and pathway analysis were conducted to identify the genes that contribute to the loss of odontogenic potential.

Results. Cultured mDMCs failed to develop into well-structured tooth when they were recombined with dental epithelium. Compared with freshly isolated mDMCs, we found that 1004 genes were upregulated and 948 were downregulated in cultured mDMCs. The differentially expressed genes were clustered in the biological processes and signaling pathways associated with tooth development. Following in vitro culture, genes encoding a wide array of components of MAPK, TGF- $\beta$ /BMP, and Wnt pathways were significantly downregulated. Moreover, the activities of $B d n f, \operatorname{Veg} f \alpha, B m p 2$, and $B m p 7$ were significantly inhibited in cultured mDMCs. Supplementation of VEGF $\alpha$, BMP2, and BMP7 restored the expression of a subset of downregulated genes and induced mDMCs to form dentin-like structures in vivo.

Conclusions. $\operatorname{Veg} f \alpha, B m p 2$, and $B m p 7$ play a role in the maintenance of odontogenic potential in mDMCs. 
 \\ INTRODUCTION}

In the field of tooth regeneration, the main concept is to mimic the natural tooth development process using stem cells. Cells or tissues with odontogenic potential are required to regenerate a whole tooth (Kollar \& Baird 1970b; Mina \& Kollar 1987). Since the odontogenic potential to instruct tooth organogenesis shifts to the dental mesenchyme at bud stage of odontogenesis (Kollar \& Baird 1970a; Mina \& Kollar 1987), and dental mesenchyme determines the tooth type and size (Kollar \& Baird 1969), it will be preferable to use a mesenchymal cell population with odontogenic potential to provide the inductive signal. Nevertheless, the adult dental stem/progenitor cells appear to lack the potency to regenerate an anatomically correct complete tooth organ (Hu et al. 2014; Mao \& Prockop 2012), and the odontogenic potential of progenitor cells derived from the embryonic stem cells or induced pluripotent stem cells was unknown (Otsu et al. 2012; Ozeki et al. 2013; Seki et al. 2015). Mouse dental mesenchymal cells (mDMCs) isolated from dental mesenchyme of cap or later stages possess the odontogenic potential and they have frequently been used in the context of developmental biology or wholetooth regeneration (Honda et al. 2007; Ikeda et al. 2009; Nakao et al. 2007). mDMCs are able to induce tooth formation in a dental or nondental epithelial cell population (Kollar \& Baird 1969; Kollar \& Baird 1970b; Wang et al. 2010; Angelova Volponi et al. 2013; Cai et al. 2013;). As the preparation of $\mathrm{mDMCs}$ is time-consuming and embryos at the right stage are not easily available, in vitro-expanded $\mathrm{mDMCs}$ could be an available cell source. However, $\mathrm{mDMCs}$ fail to support tooth development when they are grown as a monolayer (Keller et al. 2011), and the genes that contribute to the loss of odontogenic potential in mDMCs were unknown.

RNA sequencing (RNA-seq) technology provides sensitive detection of global gene expression profiles in cells and tissues, and bioinformatics approaches also examine changes in the context of the overall pathway rather than individual genes (Wang et al. 2009). To identify the genes that maintain the odontogenic potential in mDMCs, we evaluated the odontogenic potential of freshly isolated versus cultured mDMCs from the lower first molars in embryonic day 14.5 (E14.5) mice, and compared the transcriptome of freshly isolated mDMCs with that of 
91 cultured mDMCs. We found a loss of odontogenic potential accompanied by a significant

92 disturbed transcriptome in cultured mDMCs and identified potential genes that contribute to the

93 loss of odontogenic potential, providing new insight into the maintenance of odontogenic

94 potential of mDMCs. 
96

97

\section{MATERIALS \& METHODS}

\section{Cell culture}

All procedures involving animals described in the present study were reviewed and approved by the Animal Care and Use Committee of Guangzhou Institutes of Health and the Peking University in China (permit Number: CMU-B20100106). The lower first molar tooth germs were dissected from the mandibles of E14.5 mice with fine needles and treated with 0.75 $\mathrm{mg} / \mathrm{ml}$ dispase (Becton, Dickinson and Co., Franklin Lakes, $\mathrm{NJ}$ ) for $40 \mathrm{~min}$ at $37^{\circ} \mathrm{C}$ to facilitate separation from dental epithelium. The mesenchymal tissues were then incubated in $0.25 \%$ trypsin (Sigma-Aldrich, St. Louis, MO) at $37^{\circ} \mathrm{C}$ for $1 \mathrm{~min}$ and dissociated with gentle pipetting. The cells were then filtered through a $40-\mu \mathrm{m}$ cell sieve, resuspended, and cultured in Dulbecco's modified Eagle's medium (DMEM; Gibco, Grand Island, NY) plus 10\% fetal bovine serum (FBS; Gibco) (Duailibi et al. 2004; Jiang et al. 2014; Yamazaki et al. 2007; Zhao et al. 2014). To maintain the odontogenic potential of mDMCs, supplementation of VEGF $\alpha$ (Sino Biological Inc, Beijing, China), BMP2 (Sigma-Aldrich), and BMP7 (Sigma-Aldrich) were added into the medium.

\section{Quantitative reverse transcription PCR (qRT-PCR)}

Total RNA was extracted with TRIzol (Invitrogen, Carlsbad, CA) and reverse transcribed using an RT-PCR kit (TaKaRa Bio, Otsu, Japan) (Zheng et al. 2014). Quantitative PCR was performed in a Thermal CyclerDice ${ }^{\mathrm{TM}}$ Real Time System with SYBR Green Premix EXTaq ${ }^{\mathrm{TM}}$ (TaKaRa Bio). The primers used are listed in Table 1. The relative expression of genes was calculated using the $2^{-\triangle \mathrm{Ct}}$ method.

\section{Tissue recombination and subrenal culture}

The mDMCs were harvested at indicated time points using $0.25 \%$ trypsin (Sigma) and spun down to make cell pellets. The cell pellets were cultured at $37^{\circ} \mathrm{C}$ for $2-3 \mathrm{~h}$ and then recombined with freshly isolated E14.5 dental epithelium. The recombinants were further cultured in vitro for $24 \mathrm{~h}$ prior to subrenal culture in adult ICR male mice. The host mice were sacrificed 3 weeks later to harvest the grafted tissue. Grafts were then fixed and subjected to H\&E staining for 
123

124

125

126

127

128

129

130

131

132

133

134

135

136

137

138

139

140

141

142

143

144

145

146

147

148

149

histological analysis.

\section{RNA isolation and sequencing}

To determine the transcriptional regulation following in vitro culture, mDMCs from the developing molars in E14.5 mouse embryos were isolated and designated as P0. The cells were then subcultured in standard medium and passaged once they reached $90 \%$ confluence, with the first-passage culture designated as P1 and the second-passage culture as P2. P0, P1 and P2 cells were harvested using $0.25 \%$ trypsin (Sigma-Aldrich). Total RNA was extracted using the RNeasy Mini Kit and RNase-Free DNase Set according to the manufacturer's protocol (Qiagen $\mathrm{GmbH}$, Hilden, Germany). The purity and quantity of RNA were assessed using a spectrophotometer (model 8453; Agilent, Santa Clara, CA). RNA libraries for samples were prepared according to instructions for the Illumina TruSeq ${ }^{\mathrm{TM}}$ RNA Sample Prep Kit. Sequencing was performed on an Illumina Hiseq ${ }^{\mathrm{TM}} 2000$ (Illumina, San Diego, CA) in duplicate.

\section{Bioinformatics analysis}

Sequenced reads were mapped to the mouse transcriptome (mm10, Ensembl v73) and then aligned using bowtie (v1.0.1) and RSEM (v1.2.12), as described previously (Hutchins et al. 2015; Li \& Dewey 2011). EDASeq (v1.11.0) was used for GC normalization of samples, and differential expression was called using DESeq2 (v1.12.0). The fold change cut-off was set at twofold and $p$-value $<0.05$ were considered to be statistically significant. The Database for Annotation, Visualization and Integrated Discovery (DAVID) was used to determine overrepresented GO categories and KEGG pathways using the entire mouse transcriptome as the background gene set. Protein-protein interaction network of DEGs was constructed using the STRING database (http://string-db.org/). Ingenuity pathway analysis (Ingenuity Systems, CA) was used to analyze the upstream regulators of the differential expression between the samples (Razali N. et al. 2015).

\section{Statistical Analysis}

Statistical analyses were performed using SPSS PASW version 18. Experiments with cell cultures were performed at least in triplicate and data are expressed as mean \pm standard deviation 
150 (SD). The differences among groups were analyzed using one-way ANOVA. A two-tailed $p$ 151 value $<0.05$ was considered to be statistically significant. 


\section{RESULTS}

mDMCs were isolated from the developing molars in E14.5 mouse embryos and were designated as P0. One part of the P0 cells was recombined with E14.5 dental epithelium and cultured in kidney; another part was subjected to RNA-seq. The remaining cells were subcultured in standard medium, with the first-passage culture designated as P1 and the secondpassage as P2. P1 and P2 cells were also split into two portions to ensure an identical cell state for the recombination assay and the RNA-seq (Fig. 1).

\section{Odontogenic potential of cultured mouse dental mesenchymal cells}

mDMCs are typically cultured in Eagle's minimum essential medium plus fetal bovine serum and antibiotics (Jiang et al. 2014; Keller et al. 2011; Zhao et al. 2014). mDMCs showed an atypical round- or spindle-shaped fibroblast-like morphology with a higher nuclear-tocytoplasmic ratio, indicating their primitive character. Although the cells retained fibroblastic features up to the second passage, they exhibited a senescent phenotype with increased cytoplasm and augmented volume (Fig. 2A).

The odontogenic potential of P0, P1, and P2 cells were examined to identify the impact of the culturing. Although freshly isolated mDMCs developed into well-structured teeth when recombined with embryonic dental epithelium, cultured mDMCs failed to support tooth development (Fig. 2B). Moreover, the expression of genes that are essential for tooth development were analyzed using qRT-PCR. The expression of Msx $1, \operatorname{Pax} 9$, and $\operatorname{Lh} x 6$ was significantly reduced in P1 and P2 cells compared with P0 cells (Fig. 2C). The expression of $F g f 3$ and Bmp2 in cultured mDMCs was reduced compared with the $\mathrm{P} 0$ cells, but the expression of Bmp4 was not significantly different between the P0 cells and cultured mDMCs (Fig. 2D).

\section{Overview of the mouse dental mesenchymal cells' transcriptome}

To obtain a global view of genes regulating the loss of odontogenic potential, total mRNA of P0, P1, and P2 cells was extracted and sequenced. After data correction, 11,340 transcripts could be matched exactly to known mouse Ensemble transcripts. A total of 9,815 genes were shared among P0, P1 and P2 cells, whereas 563 genes were expressed exclusively in P0 cells (Fig. 3A). 
P0 cells that were not exposed to in vitro culture conditions showed a striking separation from P1 and P2 cells (Fig. 3B; Fig. S1). The transcriptional disparity between freshly isolated and cultured mDMCs is consistent with their phenotypic differences. Differential expression analysis revealed that in vitro expansion of mDMCs promoted the selective overexpression of 859 genes, whereas 763 genes were downregulated in P1 cells (Fig. 3C). Comparison of the transcriptomes of P0 and P2 cells revealed that 1004 genes were upregulated and 948 were downregulated (Fig. 3C). In contrast, 13 genes were upregulated and two genes were downregulated in P1 compared with $\mathrm{P} 2$ cells (Fig. 3C). These results suggested that the transcriptome of mDMCs was significantly influenced by in vitro culture conditions. In addition, the expression levels of Msx l, Lhx6, Pax9, Bmp4, Fgf10, Bmp2, and Fgf3 were comparable when analyzed with RNA-seq and qRT-PCR (Fig. 3D).

\section{Gene ontology analysis of differentially expressed genes}

Gene ontology (GO) analysis provides an intuitive and effective approach to understand the function of genes in three domains: biological processes, cellular components, and molecular functions. To understand the function of differentially expressed genes, GO analysis was conducted (Fig. S2) and a network diagram was created to illustrate the communication of differentially expressed genes in the enriched clusters of biological processes (Fig. 4). The network is composed of: a) genes around the node Dnmt3b, namely Dnmt1, Ezh2, Uhrf1, and $R b l 1$, which participate in chromatin organization and transcriptional regulation; b) genes around the node Runx2, namely Bmp2, Dlx1, Lhx6, and $S p 7$, involved in cell differentiation and skeletal system development; c) genes around the node Fn1, namely Robo4, Tie1, Pecam1 and col5al, involved in cell motion and cell adhesion; and d) genes that are not linked to any specific node, whose function is related to apoptosis (Tradd, Tnfrsfl1b) and epithelial morphogenesis (Grem 1). These various genes and their functions are expected because chromatin modification, cell motion, and cell adhesion are basic cellular functions involving the development of multiple organs.

\section{Pathway analysis of the differentially expressed genes}


Multiple pathways including fibroblast growth factor (FGF), bone morphogenetic protein

208

209

210

211

212

213

214

215

216

217

218

219

220

221

222

223

224

225

226

227

228

229

230

231

232

233

(BMP), hedgehog (SHH), and Wnt signaling play critical roles in odontogenesis (Liu et al. 2013;

Thesleff et al. 1995); thus the Kyoto Encyclopedia of Genes and Genomes (KEGG) pathway analysis was used to determine the pathways involving the differentially expressed genes (Fig.

$5 \mathrm{~A})$. Not surprisingly, genes showing a threefold or greater change in expression were related to the pathways regulating basic cellular activities (extracellular matrix-receptor interaction [ko04512], focal adhesion [ko04510], DNA replication [ko03030], and p53 signaling pathway [ko04115]). Notably, essential pathways regulating tooth development were also enriched, including the mitogen-activated protein kinase (MAPK) signaling pathway [ko04010], the transforming growth factor beta (TGF $\beta$ ) signaling pathway [ko04350], and the Hedgehog signaling pathway [ko04350]. However, numerous members of these signaling pathways were reduced in cultured mDMCs (Fig. 5B), and it was difficult to identify the critical regulators that are responsible for the loss of odontogenic potential in cultured mDMCs.

An upstream analysis predicts which upstream regulators were most likely to be involved based on the current levels of gene expression detected by RNA-seq analysis. Numerous upstream regulators were related to the loss of odontogenic potential in cultured mDMCs. Specifically, the activities of $B d n f, \operatorname{Veg} f \alpha, B m p 2$, and $B m p 7$ were predicted to be significantly inhibited, while $I g f 2, F g f 10$, and $T g f b 1$ were more active in cultured mDMCs (Fig. 5C). Although $B d n f$ was slightly increased in cultured $\mathrm{mDMCs}$, its receptor Ntrk2 was significantly decreased (Fig. 5B). The inhibition of $B d n f$ led to the downregulation of genes that promote odontogenesis, such as Egr1, Egr2, and Fos (Supplementary file S1). Downregulation of Bmp2 and $B m p 7$ probably contributed to the loss of odontogenic potential via the inhibition of Runx2, $S p 7$, and Msx2 (Supplementary file S1).

\section{VEGF $\alpha, B M P 2$, and BMP7 restore the expression of downregulated genes}

Given the pivotal roles of VEGF $\alpha$, BMP2, and BMP7 in tooth development, we selected these proteins to increase the expression of odontogenic genes. Indeed, tooth mesenchymespecific genes were upregulated including Msx1 and Pax9 in mDMCs treated with Bmp2 and 
234 Bmp7 (Fig. 6B; Fig. 6C). VEGF $\alpha$ slightly increased the expression of Msx1 and Pax9, but not 235 that of Lhx6 (Fig. 6A). In parallel, VEGFa, BMP2, and BMP7 were adopted to maintain the 236 odontogenic potential of mDMCs. Although well-structured tooth was not observed, dentin-like 237 structures were present (Fig. 6D). Together, VEGF $\alpha$, BMP2, and BMP7 promoted the expression 238 of dental mesenchyme-specific genes and the formation of dentin-like structures. 
239

240

241

242

243

244

245

246

247

248

249

250

251

252

253

254

255

256

257

258

259

260

261

262

263

264

265

\section{DISCUSSION}

Numerous signaling factors in dental epithelium and/or mesenchyme interact with each other to regulate odontogenesis and induce the expression of dental mesenchyme-specific transcription factors during tooth development (Thesleff et al. 1995). In the present study, we found that cultured $\mathrm{mDMCs}$ lost the odontogenic potential and failed to initiate tooth formation.

Consistently, the dental mesenchyme-specific transcription factors (Msx1, Pax9, and Lhx6) were decreased in cultured mDMCs, and the mutation of these transcription factors was shown to cause tooth agenesis disorders (Peters et al. 1998; Satokata \& Maas 1994; Zhao et al. 2013). The loss of odontogenic potential and decreased expression of dental mesenchyme-specific genes may be due to the absence of inductive signals from the dental epithelium or mesenchyme. Since Bmp and Fgf signaling pathways mediate the odontogenic inductive signals of dental mesenchyme (Liu et al. 2013; Thesleff et al. 1995), the expression of representative components within these two signaling families was analyzed in mDMCs. The expression of Bmp4 shifts from dental epithelium to mesenchyme, which is concomitant with the shift of instructive potential during tooth development (Vainio et al. 1993), but the expression of Bmp4 in the present study was not significantly changed when mDMCs were cultured in vitro. This suggests that Bmp4 in cultured mDMCs is not sufficient to substitute for the odontogenic potential and that other factors besides $B m p 4$ are responsible for the inductive potential. Similarly, although Fgf10 stimulates cell proliferation in the dental epithelium during tooth morphogenesis (Kettunen et al. 2000), the mRNA level of Fgflo was comparable between freshly-isolated and cultured mDMCs. In contrast, the expression of $F g f 3$ and $B m p 2$ in cultured mDMCs was significantly reduced. $F g f 3$ regulates the number, position, and interrelation of cusps in molar teeth; mutation of the $F g f 3$ gene leads to dosage-dependent morphological changes in teeth of both mice and human patients (Charles et al. 2009). Bmp2 is essential for the differentiation of ameloblasts and odontoblasts (Guo et al. 2015; Yang et al. 2012). Thus, the downregulation of these genes may account for the loss of odontogenic potential in cultured mDMCs. However, $B m p 2$ was expressed at a relatively low level in E14.5 mDMCs, and $F g f 3$ knockout mice do not 
266

267

268

269

270

271

272

273

274

275

276

277

278

279

280

281

282

283

284

285

286

287

288

289

290

291

292

exhibit any overt defects in teeth (Mansour et al. 1993), raising the possibility that the loss of odontogenic potential in cultured mDMCs may also involve other genes.

Transcriptome analysis, as conducted in this work, has provided insight into the molecular mechanism underlying the loss of odontogenic potential. The transcriptomic profiles reflected the potential of $\mathrm{mDMCs}$, and the mDMCs without odontogenic potential were strikingly separated from those with odontogenic potential. Moreover, the activities of $B d n f, \operatorname{Veg} f \alpha, B m p 2$, and $B m p 7$ were predicted to be inhibited. These growth factors were reported to be involved in tooth development. $B d n f$ and its receptor Ntrk2 are involved in the MAPK pathway and play roles in epithelial-mesenchymal interactions in early tooth morphogenetic events (Nosrat et al. 1997). Vegfo is an important factor that induces angiogenesis and related with the MAPK signaling pathway. It is expressed in inner enamel epithelial cells and the basement membrane (Aida et al. 2005; Miwa et al. 2007), indicating a potential role in the epithelial-mesenchymal interactions. Bmp2 promotes the maturation of odontoblasts and Bmp2 conditional knockout mice display abnormal tooth phenotypes with a hypomineralization enamel layer, delayed odontoblast differentiation, abnormal dentin tubules, and decreased tooth-related gene expression (Guo et al. 2015; Yang et al. 2012). Bmp7 is also essential for tooth development and its level in the fetal dental mesenchymal cells is higher compared with that in the adult dental pulp cells, representing a potential mediator of the inductive odontogenic potential of dental mesenchyme (Gao et al. 2015). Consistently, we found that VEGF $\alpha$, BMP2, and BMP7 increased the expression of dental mesenchyme-specific genes. Even though the supplementation with these growth factors did not restore the odontogenic potential of $\mathrm{mDMCs}$, dentin-like structures formed instead of amorphous matrix, suggesting their potential roles in the maintenance of odontogenic potential. Recently, immortalized fetal dental mesenchymal cell lines were established (Huang et al. 2015; Wu et al. 2015), and a medium supplemented with upstream signaling molecules such as $V e g f \alpha, B m p 2$, and $B m p 7$ may preserve the biological properties of mDMCs.

Although the effects of $\operatorname{Ig} f 2, F g f 10$, and $T g f b 1$ were predicted to be enhanced in cultured 
293

294

295

296

297

298

299

300

301

302

303

304

305

306

307

308

309

310

311

312

313

314

315

316

317

318

319

mDMCs, they are well-known mesenchymal signals that mediate epithelial-mesenchymal interactions during tooth development (Matsumoto et al. 2011; Nakao et al. 2013; Vaahtokari et al. 1991). Interestingly, the level of $\operatorname{Ig} f 2$ in dental mesenchyme decreased over time during development because of the hypermethylation of CpG islands (Khan et al. 2012); this suggests that the inhibition of $\operatorname{Ig} f 2$ activity is required for normal tooth development. However, further studies are still needed to investigate whether the overactivation of these factors leads to abnormal phenotype of teeth, and whether inhibitors of these factors play a role in the maintenance of odontogenic potential.

In the present study, supplementation with $V e g f, B m p 2$, and Bmp 7 did not completely restored the odontogenic potential of mDMCs. However, the GO analysis also provided a clue for the establishment of culture system for mDMCs. GO analysis showed that multiple biological processes involving the development of multiple organs were dysregulated when mDMCs were cultured in vitro. Specifically, Chromatin modifier enzymes play essential roles in the establishment of transcriptional programs accompanying cell differentiation during tooth development (Brook 2009). Mesenchymal cell migration and compaction are required to induce the expression of critical odontogenic genes and the differentiation of odontoblasts (Hu et al. 2015; Mammoto et al. 2011). The dysregulation of cell motion also contributed to the compromised potential in cultured mDMCs. Since both the mandible and teeth are mineralized tissue derived from the neural crest (Chai et al. 2000), multiple genes acting in skeletal system development have been identified as affecting the odontogenic signaling cascades (Komori 2006; Nakashima et al. 2002). Thus, Growth factors or cytokines that related with transcriptional regulation, cell differentiation or mineralization, and cell motion may facilitate the maintenance of odontogenic potential..

In conclusion, we assessed the odontogenic potential of in vitro-expanded mDMCs and conducted an analysis of their transcriptome profiles. The results revealed that the transition to an in vitro setting induced the loss of odontogenic potential and a significant modulation of the overall transcriptome. Genes encoding a wide array of components of MAPK, TGF- $\beta / \mathrm{BMP}$, and 
320 Wnt pathways were significantly downregulated in cultured cells. Our results also indicated that 321 inhibited activities of $\operatorname{Veg} f \alpha, B m p 2$, and $B m p 7$ contributed to the loss of odontogenic potential

322 and supplementation with these growth factors played roles in the maintenance of odontogenic 323 potential in mDMCs. 


\section{Availability of supporting data}

326 Raw data of the performed RNA-Seq experiments have been recorded in the GEO public

327 database (accession number: GSE65164).

328

329 Acknowledgements:

330 We thank Dr. Andrew Paul Hutchins and Dr. Xiaoshan Wang for their suggestions on data

331 analysis. We thank Prof. Xiaodong Su and Prof. Faming Chen for their suggestions on the 332 revision of the manuscript. 


\section{REFERENCES}

338

339

340

341

342

343

344

345

346

347

348

349

350

351

352

353

354

355

356

357

358

359

360

361

362

363

364

365

366

367

368

369

370

371

372

373

374

375

376

Aida M, Irie T, Aida T, and Tachikawa T. 2005. Expression of protein kinases $\mathrm{C}$ betaI, betaII, and VEGF during the differentiation of enamel epithelium in tooth development. $J$ Dent Res 84:234-239. DOI: 84/3/234.

Angelova Volponi A, Kawasaki M, and Sharpe PT. 2013. Adult human gingival epithelial cells as a source for whole-tooth bioengineering. J Dent Res 92:329-334. DOI: 10.1177/0022034513481041.

Brook AH. 2009. Multilevel complex interactions between genetic, epigenetic and environmental factors in the aetiology of anomalies of dental development. Arch Oral Biol 54 Suppl 1:S3-17. DOI: 10.1016/j.archoralbio.2009.09.005.

Cai J, Zhang Y, Liu P, Chen S, Wu X, Sun Y, Li A, Huang K, Luo R, Wang L, Liu Y, Zhou T, Wei S, Pan G, and Pei D. 2013. Generation of tooth-like structures from integration-free human urine induced pluripotent stem cells. Cell Regen (Lond) 2:6. DOI: 10.1186/2045-9769-2-615.

Chai Y, Jiang X, Ito Y, Bringas P, Jr., Han J, Rowitch DH, Soriano P, McMahon AP, and Sucov HM. 2000. Fate of the mammalian cranial neural crest during tooth and mandibular morphogenesis. Development 127:1671-1679.

Charles C, Lazzari V, Tafforeau P, Schimmang T, Tekin M, Klein O, and Viriot L. 2009. Modulation of Fgf3 dosage in mouse and men mirrors evolution of mammalian dentition. Proc Natl Acad Sci U S A 106:2236422368. DOI: 10.1073/pnas.0910086106.

Duailibi MT, Duailibi SE, Young CS, Bartlett JD, Vacanti JP, and Yelick PC. 2004. Bioengineered teeth from cultured rat tooth bud cells. J Dent Res 83:523-528. DOI: 10.1177/154405910408300703.

Gao B, Zhou X, Pi C, Xu R, Wan M, Yang J, Zhou Y, Liu C, Sun J, Zhang Y, and Zheng L. 2015. BMP7 and EREG Contribute to the Inductive Potential of Dental Mesenchyme. Sci Rep 5:9903. DOI: 10.1038/srep09903.

Guo F, Feng J, Wang F, Li W, Gao Q, Chen Z, Shoff L, Donly KJ, Gluhak-Heinrich J, Chun YH, Harris SE, MacDougall M, and Chen S. 2015. Bmp2 deletion causes an amelogenesis imperfecta phenotype via regulating enamel gene expression. J Cell Physiol 230:1871-1882. DOI: 10.1002/jcp.24915.

Honda MJ, Tsuchiya S, Sumita Y, Sagara H, and Ueda M. 2007. The sequential seeding of epithelial and mesenchymal cells for tissue-engineered tooth regeneration. Biomaterials 28:680-689. DOI: 10.1016/j.biomaterials.2006.09.039.

Hu S, Parker J, and Wright JT. 2015. Towards unraveling the human tooth transcriptome: the dentome. PLoS One 10:e0124801. DOI: 10.1371/journal.pone.0124801.

Hu X, Lin C, Shen B, Ruan N, Guan Z, Chen Y, and Zhang Y. 2014. Conserved odontogenic potential in embryonic dental tissues. J Dent Res 93:490-495. DOI: 10.1177/0022034514523988.

Huang Y, Yang Y, Jiang M, Lin M, Li S, and Lin Y. 2015. Immortalization and characterization of human dental mesenchymal cells. J Dent 43:576-582. DOI: 10.1016/j.jdent.2015.02.008.

Hutchins AP, Takahashi Y, and Miranda-Saavedra D. 2015. Genomic analysis of LPS-stimulated myeloid cells identifies a common pro-inflammatory response but divergent IL-10 anti-inflammatory responses. Sci Rep 5:9100. DOI: 10.1038/srep09100.

Ikeda E, Morita R, Nakao K, Ishida K, Nakamura T, Takano-Yamamoto T, Ogawa M, Mizuno M, Kasugai S, and Tsuji T. 2009. Fully functional bioengineered tooth replacement as an organ replacement therapy. Proc Natl Acad Sci U S A 106:13475-13480. DOI: 10.1073/pnas.0902944106.

Jiang N, Zhou J, Chen M, Schiff MD, Lee CH, Kong K, Embree MC, Zhou Y, and Mao JJ. 2014. Postnatal epithelium and mesenchyme stem/progenitor cells in bioengineered amelogenesis and dentinogenesis. 
Biomaterials 35:2172-2180. DOI: 10.1016/j.biomaterials.2013.11.061.

Keller L, Kuchler-Bopp S, Mendoza SA, Poliard A, and Lesot H. 2011. Tooth engineering: searching for dental mesenchymal cells sources. Front Physiol 2:7. DOI: 10.3389/fphys.2011.00007.

Kettunen P, Laurikkala J, Itaranta P, Vainio S, Itoh N, and Thesleff I. 2000. Associations of FGF-3 and FGF-10 with signaling networks regulating tooth morphogenesis. Dev Dyn 219:322-332. DOI: 10.1002/10970177(2000)9999:9999<::AID-DVDY1062>3.0.CO;2-J.

Khan QE, Sehic A, Skalleberg N, Landin MA, Khuu C, Risnes S, and Osmundsen H. 2012. Expression of delta-like 1 homologue and insulin-like growth factor 2 through epigenetic regulation of the genes during development of mouse molar. Eur J Oral Sci 120:292-302. DOI: 10.1111/j.1600-0722.2012.00976.

Kollar EJ, and Baird GR. 1969. The influence of the dental papilla on the development of tooth shape in embryonic mouse tooth germs. J Embryol Exp Morphol 21:131-148.

Kollar EJ, and Baird GR. 1970a. Tissue interactions in embryonic mouse tooth germs. I. Reorganization of the dental epithelium during tooth-germ reconstruction. J Embryol Exp Morphol 24:159-171.

Kollar EJ, and Baird GR. 1970b. Tissue interactions in embryonic mouse tooth germs. II. The inductive role of the dental papilla. J Embryol Exp Morphol 24:173-186.

Komori T. 2006. Regulation of osteoblast differentiation by transcription factors. Journal of Cellular Biochemistry 99:1233-1239. DOI: 10.1002/jcb.20958.

Li B, and Dewey CN. 2011. RSEM: accurate transcript quantification from RNA-Seq data with or without a reference genome. BMC Bioinformatics 12:323. DOI: 10.1186/1471-2105-12-323.

Liu C, Gu S, Sun C, Ye W, Song Z, Zhang Y, and Chen Y. 2013. FGF signaling sustains the odontogenic fate of dental mesenchyme by suppressing beta-catenin signaling. Development 140:4375-4385. DOI: 10.1242/dev.097733.

Mammoto T, Mammoto A, Torisawa YS, Tat T, Gibbs A, Derda R, Mannix R, de Bruijn M, Yung CW, Huh D, and Ingber DE. 2011. Mechanochemical control of mesenchymal condensation and embryonic tooth organ formation. Dev Cell 21:758-769. DOI: 10.1016/j.devcel.2011.07.006.

Mansour SL, Goddard JM, and Capecchi MR. 1993. Mice homozygous for a targeted disruption of the protooncogene int-2 have developmental defects in the tail and inner ear. Development 117:13-28.

Mao JJ, and Prockop DJ. 2012. Stem cells in the face: tooth regeneration and beyond. Cell Stem Cell 11:291-301. DOI: $10.1016 /$ j.stem.2012.08.010.

Matsumoto A, Harada H, Saito M, and Taniguchi A. 2011. Induction of insulin-like growth factor 2 expression in a mesenchymal cell line co-cultured with an ameloblast cell line. In Vitro Cell Dev Biol Anim 47:675-680. DOI: 10.1007/s11626-011-9456-x

Mina M, and Kollar EJ. 1987. The induction of odontogenesis in non-dental mesenchyme combined with early murine mandibular arch epithelium. Arch Oral Biol 32:123-127.

Miwa Y, Shimada K, Sunohara M, and Sato I. 2007. Immunohistochemically localization of vascular endothelial growth factor, vascular endothelial growth factor receptor-2, collagen I and fibronectin in the epitheliamesenchymal junction of the human tooth germ. Okajimas Folia Anat Jpn 84:107-110. DOI: 10.2535/ofaj.84.107.

Nakao K, Morita R, Saji Y, Ishida K, Tomita Y, Ogawa M, Saitoh M, Tomooka Y, and Tsuji T. 2007. The development of a bioengineered organ germ method. Nat Methods 4:227-230. DOI: 10.1038/nmeth1012.

Nakao Y, Mitsuyasu T, Kawano S, Nakamura N, Kanda S, and Nakamura S. 2013. Fibroblast growth factors 7 and 
10 are involved in ameloblastoma proliferation via the mitogen-activated protein kinase pathway. Int J Oncol 43:1377-1384. DOI: 10.3892/ijo.2013.2081.

Nakashima K, Zhou X, Kunkel G, Zhang Z, Deng JM, Behringer RR, and de Crombrugghe B. 2002. The novel zinc finger-containing transcription factor osterix is required for osteoblast differentiation and bone formation. Cell 108:17-29. DOI: 10.1016/S0092-8674(01)00622-5.

Nosrat CA, Fried K, Lindskog S, and Olson L. 1997. Cellular expression of neurotrophin mRNAs during tooth development. Cell Tissue Res 290:569-580. DOI: 10.1007/s004410050962.

Otsu K, Kishigami R, Oikawa-Sasaki A, Fukumoto S, Yamada A, Fujiwara N, Ishizeki K, and Harada H. 2012. Differentiation of induced pluripotent stem cells into dental mesenchymal cells. Stem Cells Dev 21:1156-1164. DOI: $10.1089 / \mathrm{scd} .2011 .0210$.

Ozeki N, Mogi M, Kawai R, Yamaguchi H, Hiyama T, Nakata K, and Nakamura H. 2013. Mouse-induced pluripotent stem cells differentiate into odontoblast-like cells with induction of altered adhesive and migratory phenotype of integrin. PLoS One 8:e80026. DOI: 10.1371/journal.pone.0080026.

Razali N., Aziz AA., Lim CY., and SM. J. 2015. Investigation into the effects of antioxidant-rich extract of Tamarindus indica leaf on antioxidant enzyme activities, oxidative stress and gene expression profiles in HepG2 cells. PeeJ 3:e1292. DOI 10.7717/peerj.1292.

Peters H, Neubuser A, Kratochwil K, and Balling R. 1998. Pax9-deficient mice lack pharyngeal pouch derivatives and teeth and exhibit craniofacial and limb abnormalities. Genes Dev 12:2735-2747. DOI: 10.1101/gad.12.17.2735.

Satokata I, and Maas R. 1994. Msx1 deficient mice exhibit cleft palate and abnormalities of craniofacial and tooth development. Nat Genet 6:348-356. DOI: 10.1038/ng0494-348.

Seki D, Takeshita N, Oyanagi T, Sasaki S, Takano I, Hasegawa M, and Takano-Yamamoto T. 2015. Differentiation of Odontoblast-Like Cells From Mouse Induced Pluripotent Stem Cells by Pax 9 and Bmp4 Transfection. Stem Cells Transl Med. sctm. 2014-0292. DOI: 10.5966/sctm.2014-0292

Thesleff I, Vaahtokari A, and Partanen AM. 1995. Regulation of organogenesis. Common molecular mechanisms regulating the development of teeth and other organs. Int J Dev Biol 39:35-50.

Vaahtokari A, Vainio S, and Thesleff I. 1991. Associations between transforming growth factor beta 1 RNA expression and epithelial-mesenchymal interactions during tooth morphogenesis. Development 113:985-994.

Vainio S, Karavanova I, Jowett A, and Thesleff I. 1993. Identification of BMP-4 as a signal mediating secondary induction between epithelial and mesenchymal tissues during early tooth development. Cell 75:45-58. DOI: 0092-8674(93)90678-J.

Wang B, Li L, Du S, Liu C, Lin X, Chen Y, and Zhang Y. 2010. Induction of human keratinocytes into enamelsecreting ameloblasts. Dev Biol 344:795-799. DOI: 10.1016/j.ydbio.2010.05.511.

Wang Z, Gerstein M, and Snyder M. 2009. RNA-Seq: a revolutionary tool for transcriptomics. Nat Rev Genet 10:57-63. DOI: $10.1038 / \operatorname{nrg} 2484$.

Wu L, Wang F, Donly KJ, Wan C, Luo D, Harris SE, MacDougall M, and Chen S. 2015. Establishment of Immortalized Mouse Bmp2 Knock-out Dental Papilla Mesenchymal Cells Necessary for Study of Odontoblastic Differentiation and Odontogenesis. J Cell Physiol. DOI: 10.1002/jcp.25061.

Yamazaki H, Tsuneto M, Yoshino M, Yamamura K, and Hayashi S. 2007. Potential of dental mesenchymal cells in developing teeth. Stem Cells 25:78-87. DOI: 10.1634/stemcells.2006-0360.

Yang W, Harris MA, Cui Y, Mishina Y, Harris SE, and Gluhak-Heinrich J. 2012. Bmp2 is required for odontoblast 
459 differentiation and pulp vasculogenesis. J Dent Res 91:58-64. DOI: 10.1177/0022034511424409.

460 Zhao H, Feng J, Seidel K, Shi S, Klein O, Sharpe P, and Chai Y. 2014. Secretion of shh by a neurovascular bundle 461 niche supports mesenchymal stem cell homeostasis in the adult mouse incisor. Cell Stem Cell 14:160-173. DOI:

$462 \quad$ 10.1016/j.stem.2013.12.013.

463 Zhao M, Gupta V, Raj L, Roussel M, and Bei M. 2013. A network of transcription factors operates during early 464 tooth morphogenesis. Mol Cell Biol 33:3099-3112. DOI: 10.1128/MCB.00524-13.

465 Zheng Y, Hou J, Peng L, Zhang X, Jia L, Wang X, Wei S, and Meng H. 2014. The pro-apoptotic and pro-

466 inflammatory effects of calprotectin on human periodontal ligament cells. PLoS One 9:e110421. DOI:

467 10.1371/journal.pone.0110421.

468

469 
471

472

473

474

475

476

477

478

479

480

481

482

\section{Figure Legends}

Figure 1 Experimental design. Tooth germs from embryonic day 14.5 mice were obtained and digested with dispase to separate the dental mesenchyme from dental epithelium. Freshly isolated dental mesenchymal cells were designated as P0 and cultured in vitro. RNA samples from the $\mathrm{P} 0$, the first $(\mathrm{P} 1)$, and second $(\mathrm{P} 2)$ passages were collected before they were submitted for RNA-seq using an Illumina Hiseq ${ }^{\mathrm{TM}} 2000$.

Figure 2 The odontogenic potential is impaired in the cultured mDMCs. (A) mDMCs possessed a fibroblastic-like morphology, and the nuclear-to-cytoplasmic ratio of the P1 and P2 cells was relatively smaller compared with the P0 cells. (B) The P0 cells developed into wellstructured teeth when reassociated with dental epithelium, whereas the P1 and P2 cells failed to support tooth development as revealed by the stereoscopic microscopes (upper panel) or HE staining (lower panel; D, dentin; OD, odontoblast; DP, dental pulp; M, matrix. scale bar: upper 1 mm, lower $50 \mu \mathrm{m}$ ). (C) The mRNA levels of Msx1, Pax9, and Lhx6 in mDMCs. (D) The mRNA levels of Bmp4, Fgf10, Bmp2, and Fgf3 in mDMCs. Data are expressed as the mean \pm standard deviation (SD). $* p<0.05$.

\section{Figure 3 Comparison of the transcriptomic profiles of freshly isolated and cultured} mDMCs. (A) The Venn diagram shows the expression profiling of P0, P1 and P2 cells, with each section showing the number of genes. (B) Hierarchical clustering analysis showed that the P1 and P2 were highly correlated, whereas the P0 was independent of them. (C) The number of differentially-expressed genes is illustrated. (D) The expression levels of $M s x 1, \operatorname{Lh} x 6, \operatorname{Pax} 9$, Bmp4, Fgf10, Bmp2, and Fgf3 were comparable when analyzed with RNA-seq and qRT-PCR. Data are expressed as the mean \pm standard deviation (SD). $* p<0.05$.

Figure 4 Gene ontology (GO) analysis of the differentially expressed genes. A proteinprotein interaction network was constructed. DEGs in enriched GO categories are represented in the network.

Figure 5 Disturbed pathways and the upstream regulators. (A) Kyoto Encyclopedia of Genes and Genomes (KEGG) pathways involving the differentially expressed genes are listed. (B) A 
498 heat map representing the genes within the MAPK, Wnt, and TGF $\beta$ pathways. (C) The upstream 499 regulators predicted by Ingenuity pathway analysis.

500 Figure 6 VEGF $\alpha$, BMP2, and BMP7 play roles in the maintenance of odontogenic potential.

501 The mRNA levels of dental mesenchyme-specific genes in mDMCs cultured in the medium

502 supplemented with $10 \mathrm{ng} / \mathrm{ml}$ or $50 \mathrm{ng} / \mathrm{ml} \mathrm{VEGF \alpha} \mathrm{(A),} \mathrm{BMP2} \mathrm{(B),} \mathrm{and} \mathrm{BMP7} \mathrm{(C).} \mathrm{(D)}$

503 Stereoscopic images (upper) and histological images (lower) of the dentin-like structures or the

504 amorphous matrix. Dentin-like structures derived from recombinants with mDMCs cultured in 505 the medium supplemented with VEGF $\alpha$, BMP2, and BMP7 (VBB). D, dentin-like structures; M, 506 amorphous matrix; NC, negative control. Data are expressed as the mean \pm standard deviation 507 (SD). ${ }^{*} p<0.05$. Scale bar: upper left $1 \mathrm{~mm}$, upper right $500 \mu \mathrm{m}$, lower $50 \mu \mathrm{m}$. 


\section{1}

Experimental design.

Tooth germs from embryonic day 14.5 mice were obtained and digested with dispase to separate the dental mesenchyme from dental epithelium. Freshly isolated dental mesenchymal cells were designated as P0 and cultured in vitro. RNA samples from the PO, the first (P1), and second (P2) passages were collected before they were submitted for RNAseq using an Illumina Hiseq ${ }^{\text {TM }} 2000$.

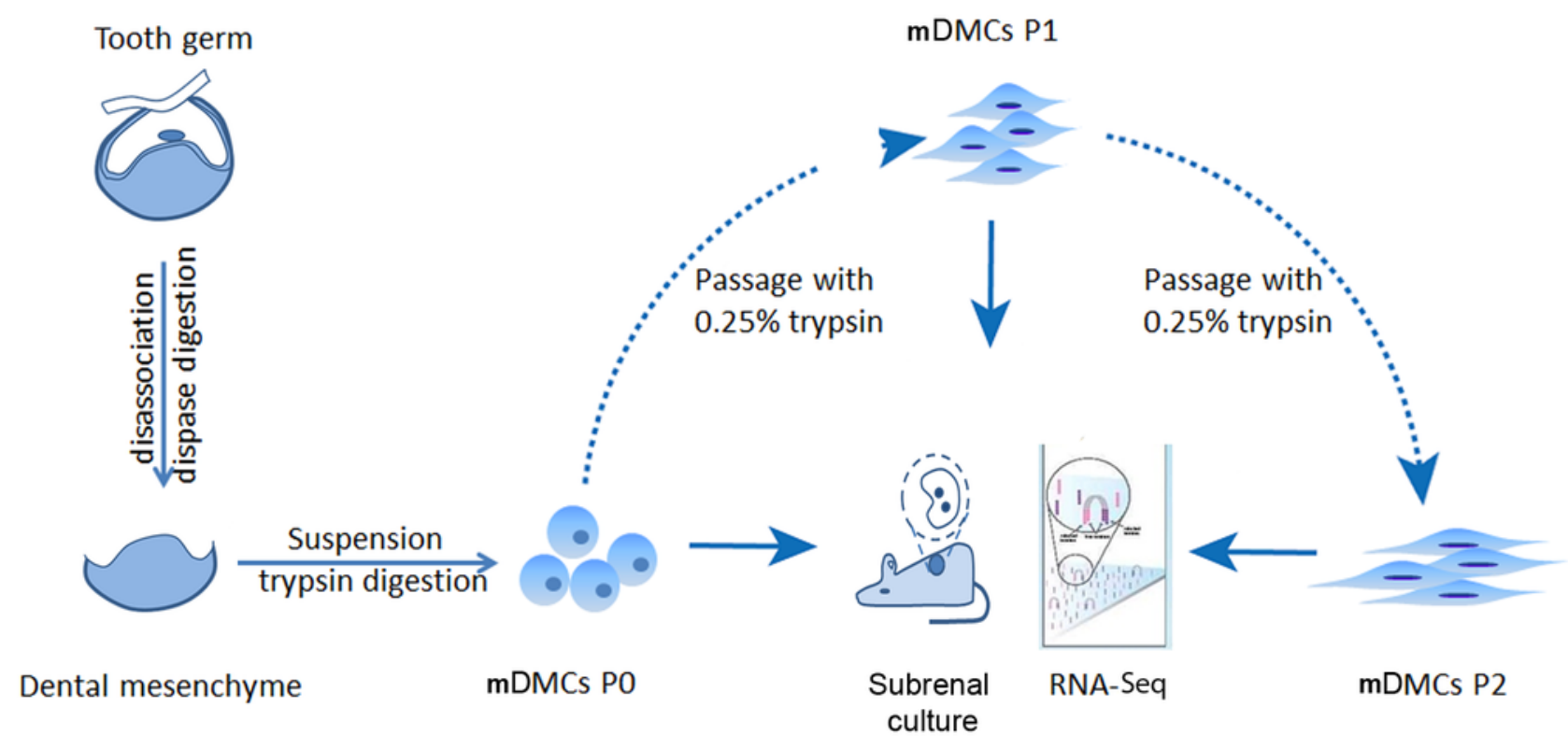


2

The odontogenic potential is impaired in the cultured mDMCs.

(A) mDMCs possessed a fibroblastic-like morphology, and the nuclear-to-cytoplasmic ratio of the P1 and P2 cells was relatively smaller compared with the P0 cells. (B) The P0 cells developed into well-structured teeth when reassociated with dental epithelium, whereas the $\mathrm{P} 1$ and P2 cells failed to support tooth development as revealed by the stereoscopic microscopes (upper panel) or HE staining (lower panel; D, dentin; OD, odontoblast; DP, dental pulp; M, matrix. scale bar: upper $1 \mathrm{~mm}$, lower $50 \mu \mathrm{m}$ ). (C) The mRNA levels of Msx1, Pax9, and Lhx6 in mDMCs. (D) The mRNA levels of Bmp4, Fgf10, Bmp2, and Fgf3 in mDMCs. Data are expressed as the mean \pm standard deviation (SD). ${ }^{*} p<0.05$. 
A
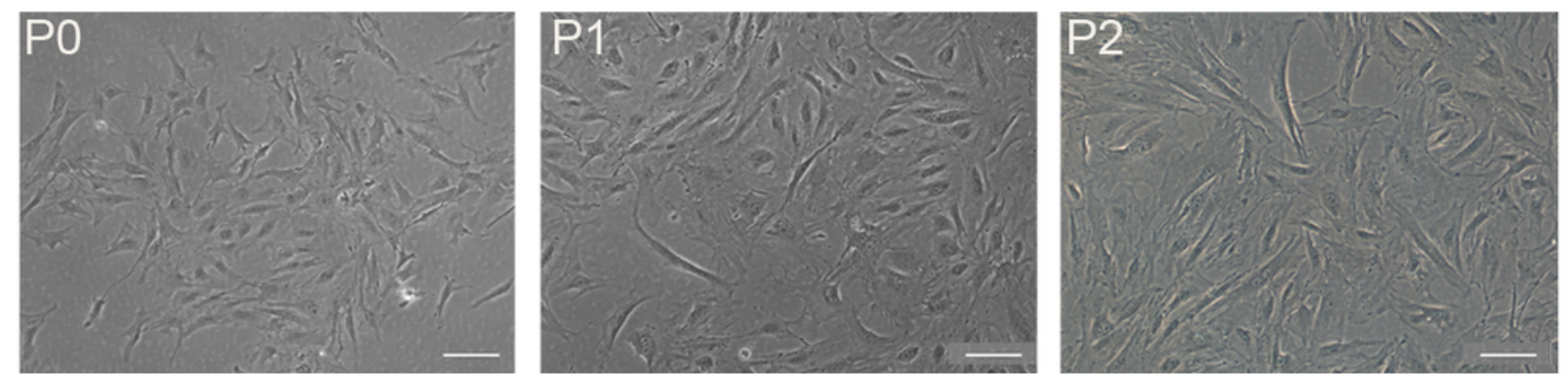

B
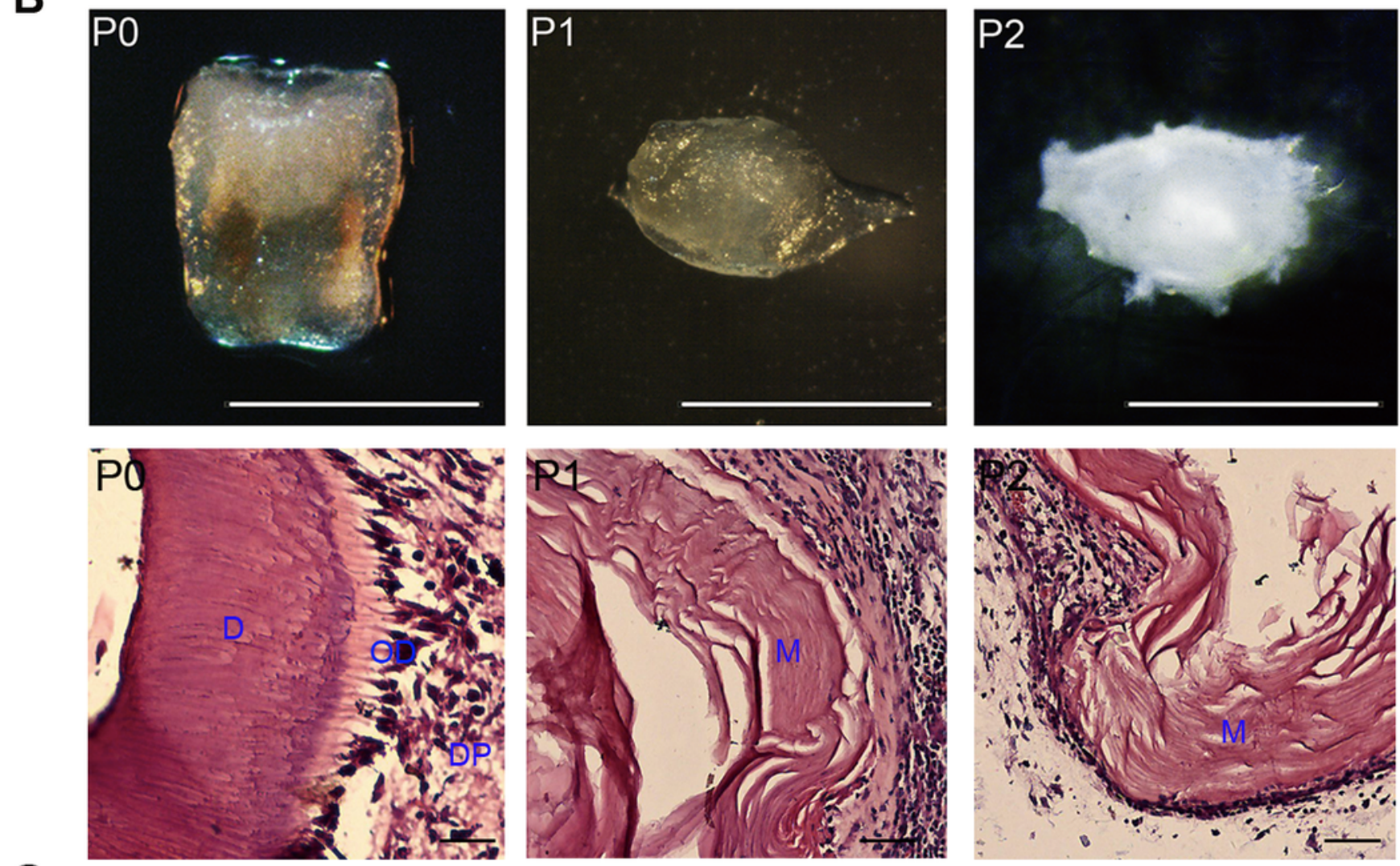

C

D
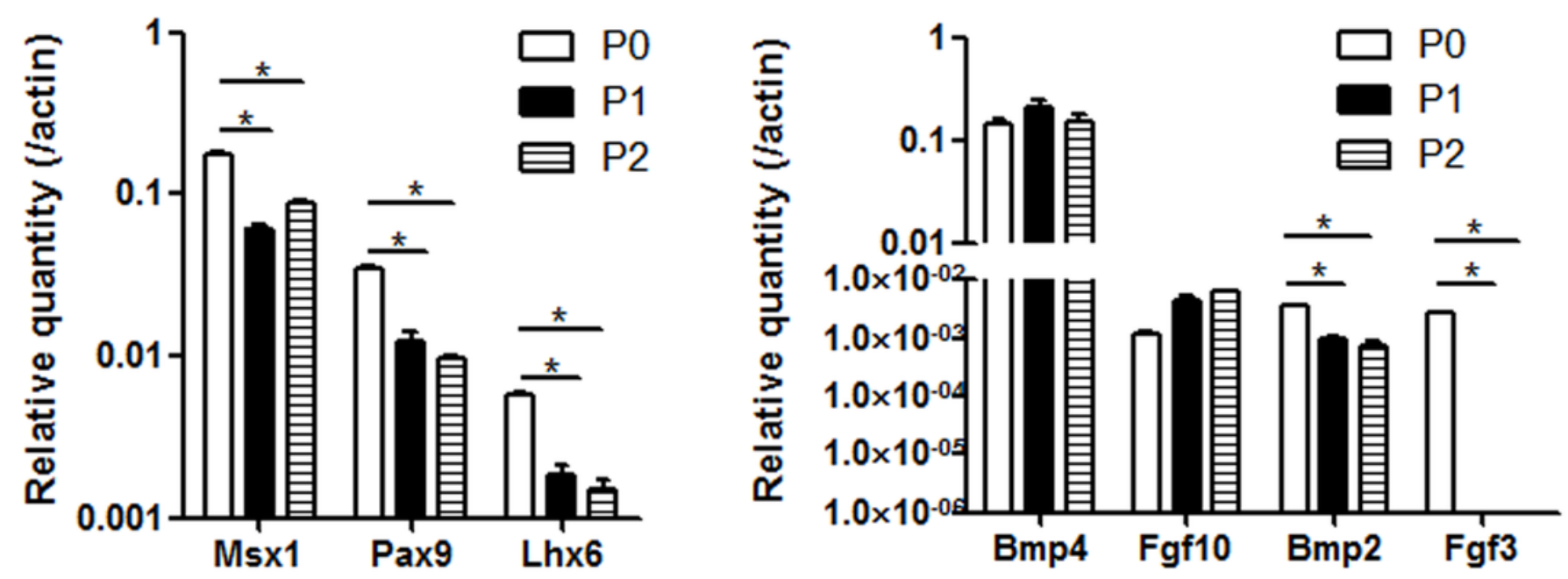
3

Comparison of the transcriptomic profiles of freshly isolated and cultured mDMCs.

(A) The Venn diagram shows the expression profiling of P0, P1 and P2 cells, with each section showing the number of genes. (B) Hierarchical clustering analysis showed that the P1 and P2 were highly correlated, whereas the P0 was independent of them. (C) The number of differentially-expressed genes is illustrated. (D) The expression levels of Msx1, Lhx6, Pax9, Bmp4, Fgf10, Bmp2, and Fgf3 were comparable when analyzed with RNA-seq and qRT-PCR. Data are expressed as the mean \pm standard deviation (SD). ${ }^{*} p<0.05$. 
A

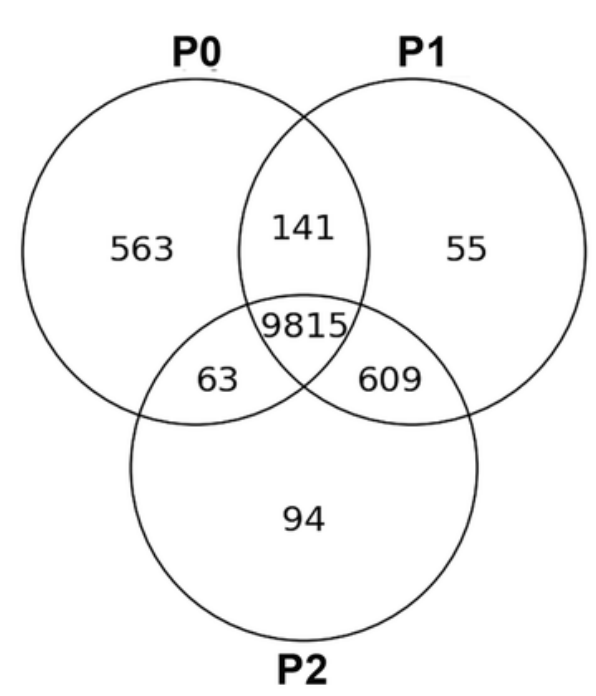

B
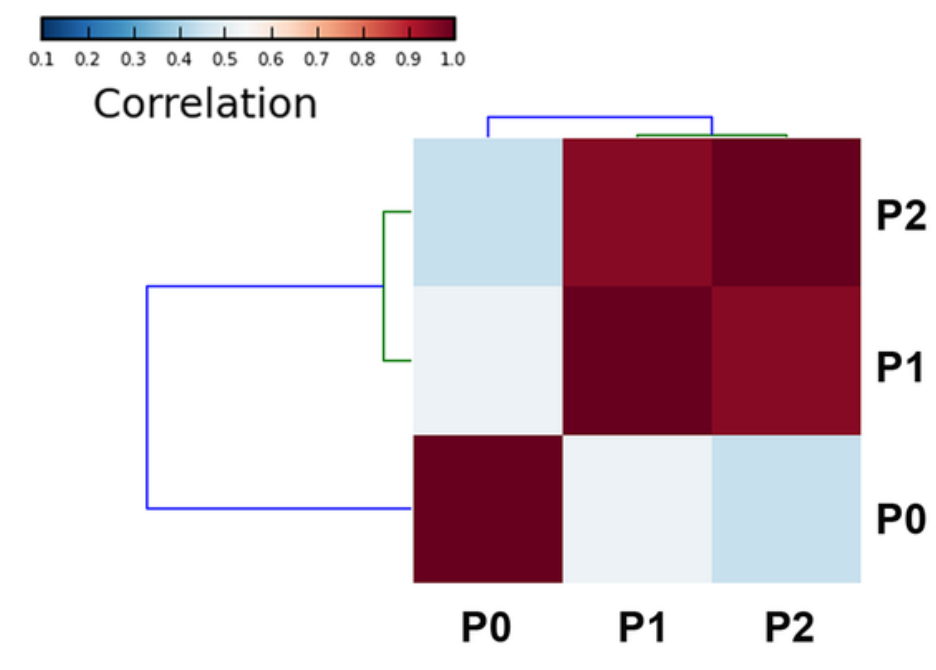

C

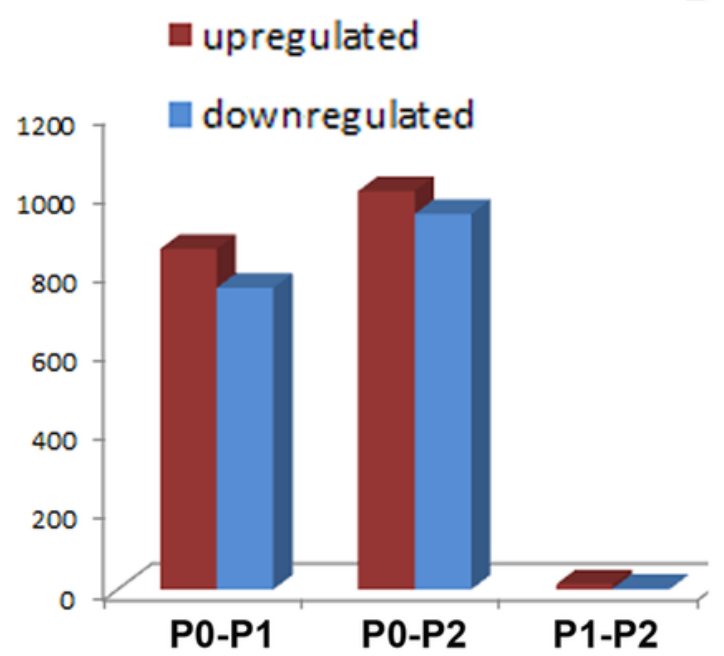

D

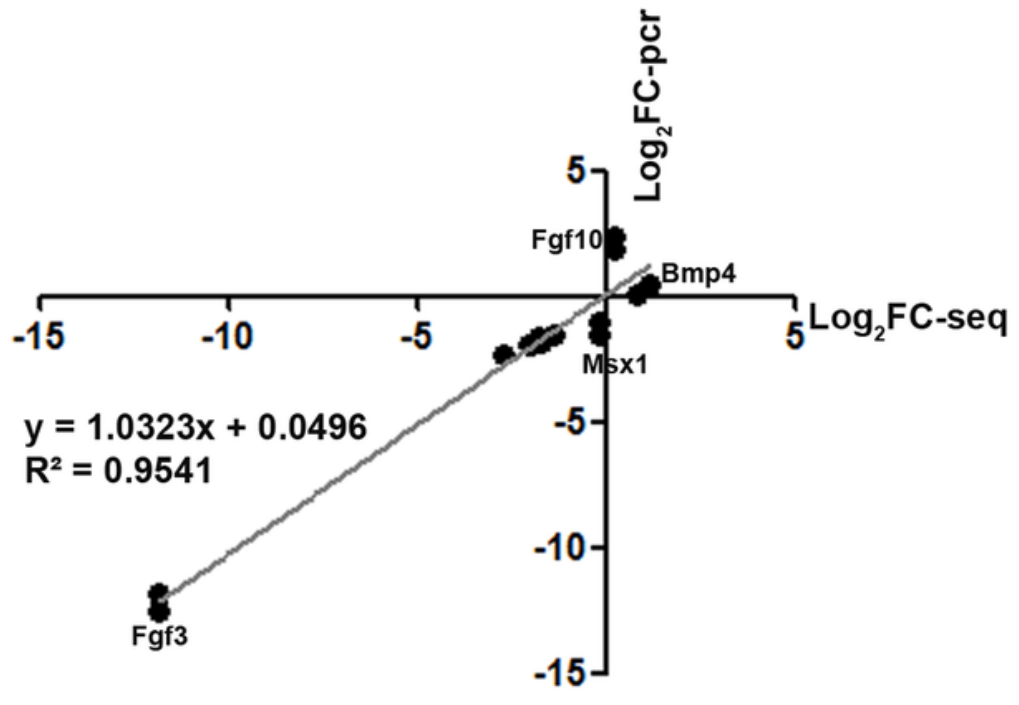


4

Gene ontology (GO) analysis of the differentially expressed genes.

A protein-protein interaction network was constructed. DEGs in enriched GO categories are represented in the network.

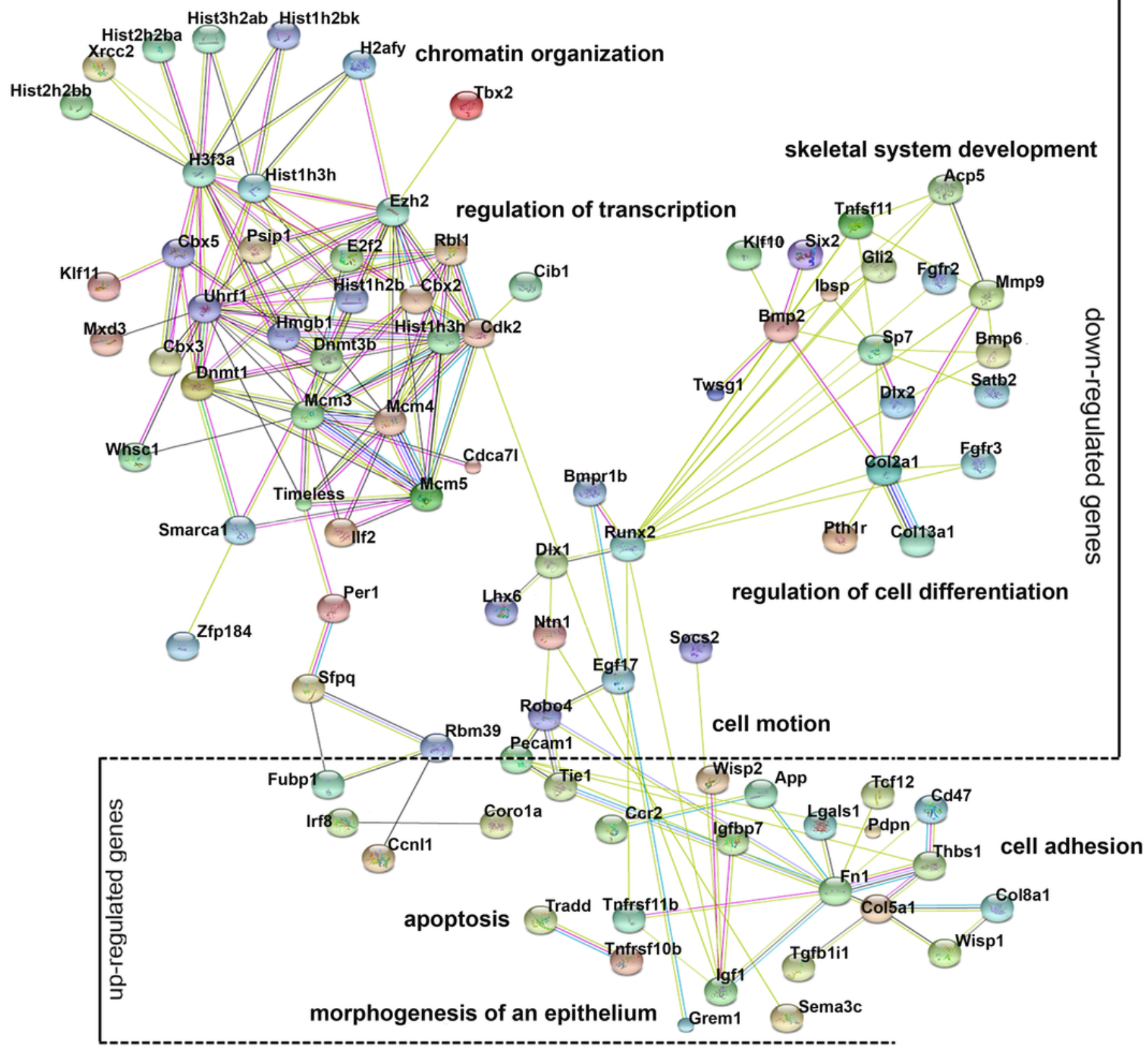




\section{5}

Disturbed pathways and the upstream regulators.

(A) Kyoto Encyclopedia of Genes and Genomes (KEGG) pathways involving the differentially expressed genes are listed. (B) A heat map representing the genes within the MAPK, Wnt, and TGF $\beta$ pathways. (C) The upstream regulators predicted by Ingenuity pathway analysis.

A
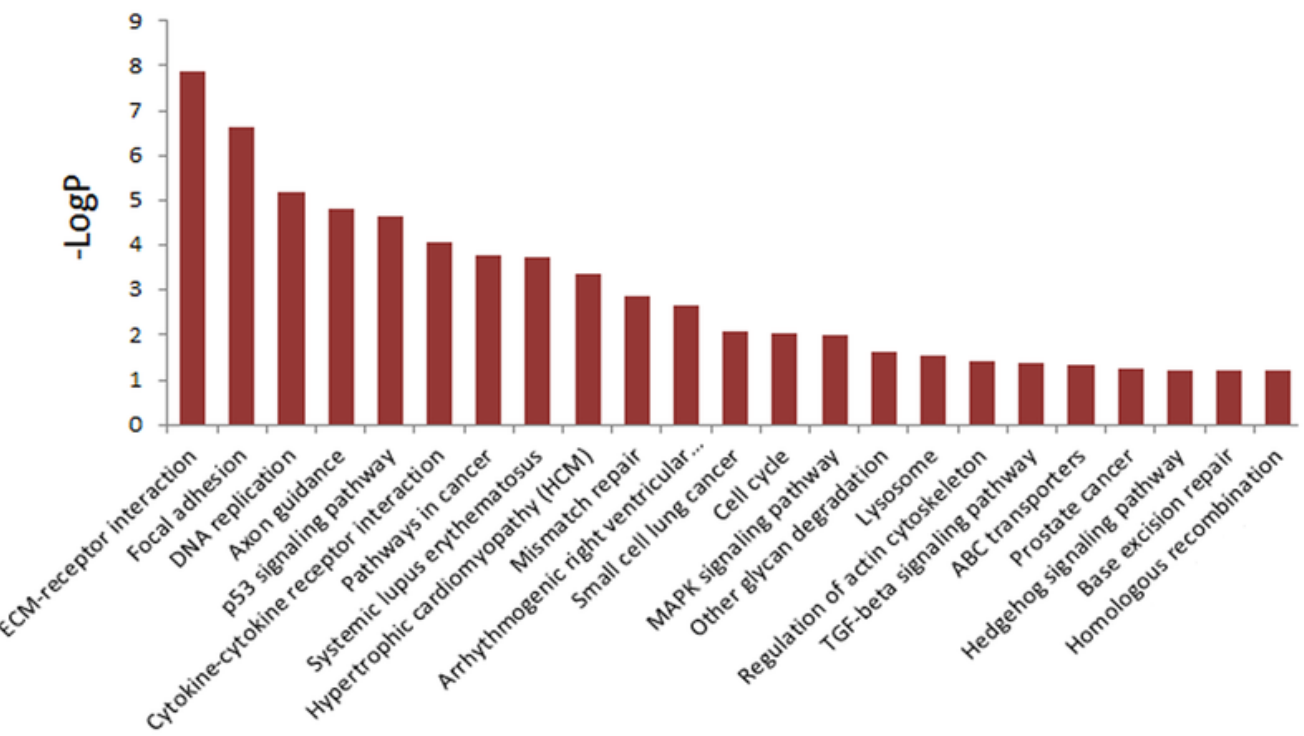

C

\begin{tabular}{|c|c|c|c|}
\hline Gene Name & Predicted Activation & Activation Score & P-Value \\
\hline Bdnf & Inhibited & -2.641 & $2.00 \mathrm{E}-24$ \\
\hline Vegfa & Inhibited & -1.735 & $5.21 \mathrm{E}-20$ \\
\hline Bmp2 & Inhibited & -1.236 & $2.12 \mathrm{E}-14$ \\
\hline Bmp7 & Inhibited & -1.256 & $1.95 \mathrm{E}-11$ \\
\hline Igf2 & Activated & 2.126 & $4.27 \mathrm{E}-17$ \\
\hline Fgf10 & Activated & 3.344 & $7.72 \mathrm{E}-07$ \\
\hline Tgfß & Activated & 4.128 & $1.06 \mathrm{E}-84$ \\
\hline
\end{tabular}

B $2.4-160.000008162432$
expression

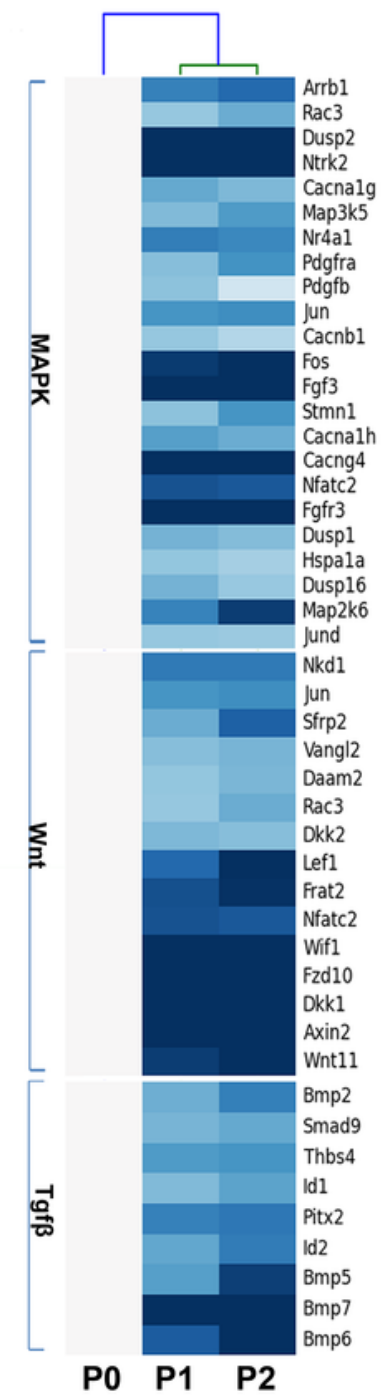


6

VEGF $\alpha, B M P 2$, and BMP7 play roles in the maintenance of odontogenic potential.

The mRNA levels of dental mesenchyme-specific genes in mDMCs cultured in the medium supplemented with $10 \mathrm{ng} / \mathrm{ml}$ or $50 \mathrm{ng} / \mathrm{ml} \mathrm{VEGF \alpha} \mathrm{(A),} \mathrm{BMP2} \mathrm{(B),} \mathrm{and} \mathrm{BMP7} \mathrm{(C).} \mathrm{(D)}$

Stereoscopic images (upper) and histological images (lower) of the dentin-like structures or the amorphous matrix. Dentin-like structures derived from recombinants with mDMCs cultured in the medium supplemented with VEGF $\alpha, B M P 2$, and BMP7 (VBB). D, dentin-like structures; M, amorphous matrix; NC, negative control. Data are expressed as the mean \pm standard deviation (SD). ${ }^{*} p<0.05$. Scale bar: upper left $1 \mathrm{~mm}$, upper right $500 \mu \mathrm{m}$, lower $50 \mu \mathrm{m}$.

A

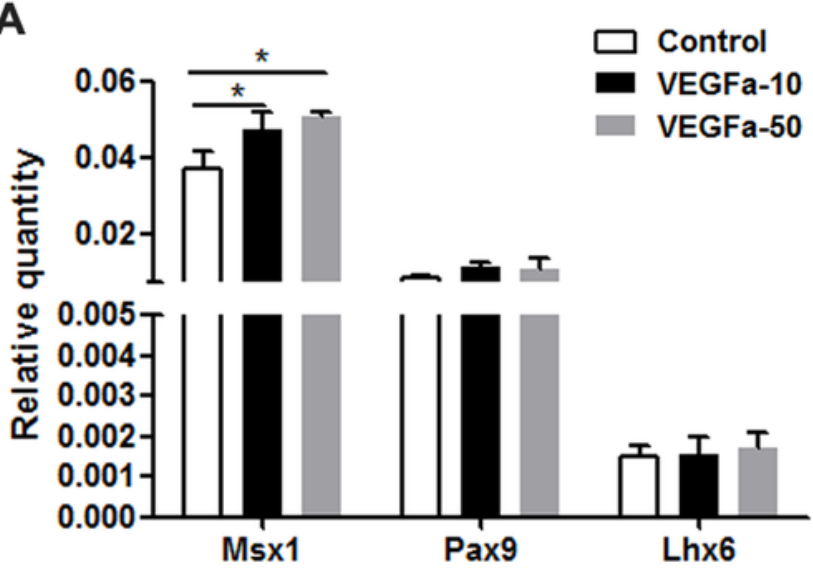

C

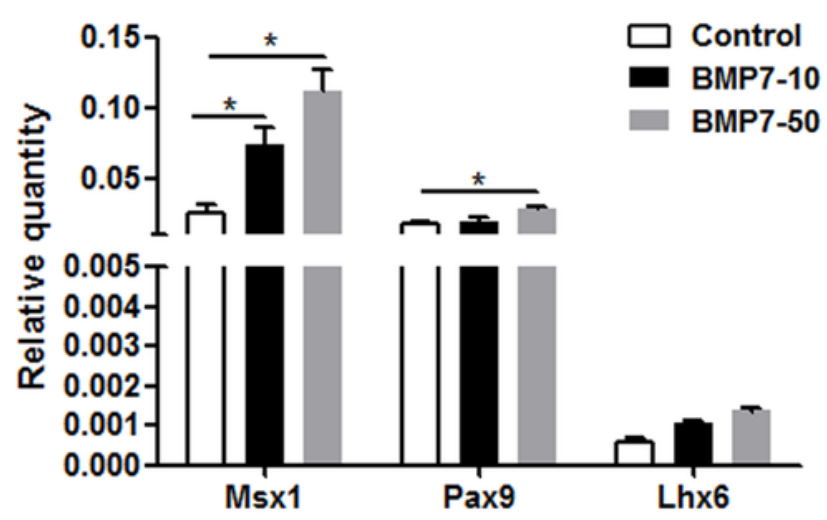

B

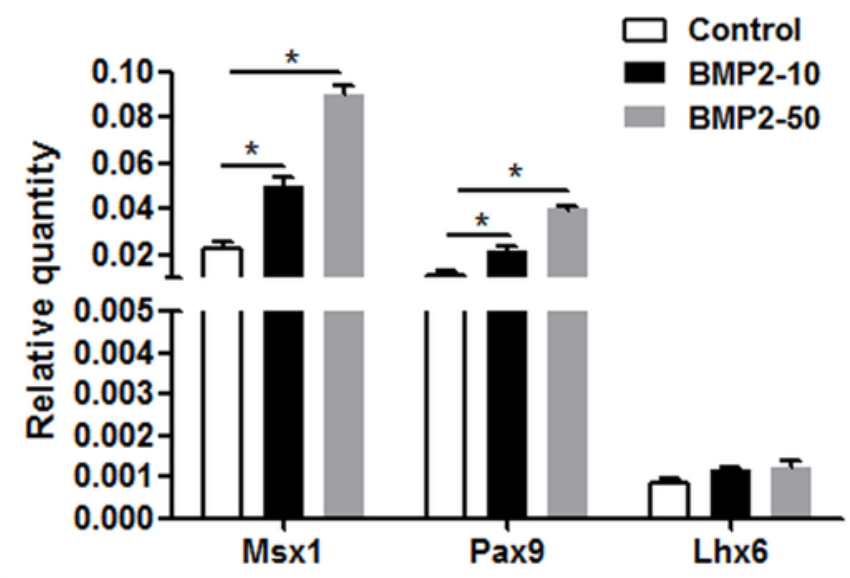

D

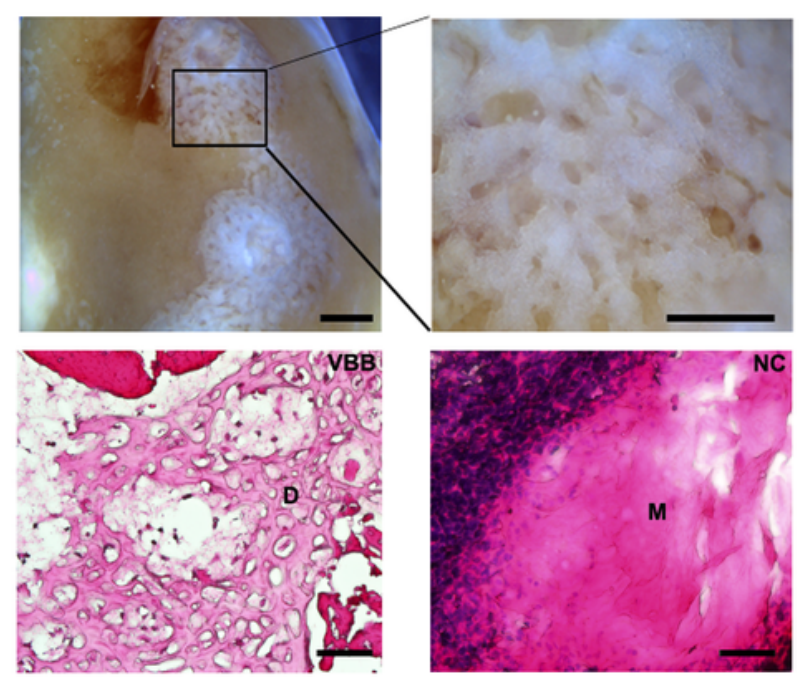


Table $\mathbf{1}$ (on next page)

Primers for quantitative real-time PCR. 
1 Table 1 | Primers for quantitative real-time PCR.

\begin{tabular}{lll}
\hline & Forward & \multicolumn{2}{l}{ Reverse } \\
\hline Gapdh & 5'-TGG CCT TCC GTG TTC CTA C-3' & 5'-GAG TTG CTG TTG AAG TCG CA-3' \\
Lhx6 & 5'-CAT TGA GAG TCA GGT ACA GTG C-3' & 5'-GGG CCG TCC AAA TCA GCT T-3' \\
Bmp4 & 5'-TTC CTG GTA ACC GAA TGC TGA-3' & 5'-CCT GAA TCT CGG CGA CTT TTT-3' \\
Msx1 & 5'- GCA CAA GAC CAA CCG CAAG-3' & 5'- CGC TCG GCA ATA GAC AGG T-3' \\
Pax9 & 5'-CAT TCG GCT TCG CAT CGT G -3' & 5'-CTC CCG GCA AAA TCG AAC C-3' \\
Fgf10 & 5'- GCA GGC AAA TGT ATG TGG CAT-3' & 5'- ATG TTT GGA TCG TCA TGG GGA-3' \\
Bmp2 & 5'-GGG ACC CGC TGT CTT CTA GT-3' & 5'-TCA ACT CAA ATT CGC TGA GGA C-3' \\
Fgf3 & 5'-TGC GCT ACC AAG TAC CAC C-3' & 5'-CAC TTC CAC CGC AGT AAT CTC-3' \\
\hline
\end{tabular}

2

3

4 